\title{
Limited Dose-Effect Relationship of Adenosine for Detection of Atrioventricular Nodal Duality in Patients with Supraventricular Tachycardias
}

\author{
Christiana Schernthaner Maximilian Pichler Bernhard Strohmer \\ Department of Cardiology, Salzburger Landeskliniken, Paracelsus Private Medical University, Salzburg, Austria
}

\section{Key Words}

Adenosine $\cdot$ Atrioventricular nodal duality $\cdot$ Atrioventricular nodal reentrant tachycardia $\cdot$ Supraventricular tachycardia

\begin{abstract}
Objective: The purpose of the study was to test the dose-effect relationship of adenosine for the diagnosis of dual atrioventricular (AV) nodal physiology in patients presenting with supraventricular tachycardia. Subjects and Methods: The study population consisted of 57 patients (mean age 50 \pm 14 years; 36 females, 21 males) with palpitations related to supraventricular tachycardia. Adenosine was injected as bolus during sinus rhythm at rest in order to unmask dual AV nodal physiology by a PR jump on surface ECG (defined as a sudden increase by $\geq 50 \mathrm{~ms}$ measured from the onset of the $\mathrm{P}$-wave to the R-wave between two consecutive sinus beats). According to a stepwise clinical approach, adenosine was administered as bolus in incremental dosages $(6 \mathrm{mg}$ followed by $12 \mathrm{mg}$, if necessary up to $18 \mathrm{mg}$ ). Once a PR jump $\geq 50$ ms or a high-grade AV block was noted on surface ECG, the injection was stopped at that dose. Results: A significant PR jump was noted after injection of $6 \mathrm{mg}(\mathrm{n}=21,99 \pm 30$ $\mathrm{ms})$ or $12 \mathrm{mg}(\mathrm{n}=13,94 \pm 35 \mathrm{~ms})$, but not after $18 \mathrm{mg}(\mathrm{n}=$ $4,35 \pm 10 \mathrm{~ms}$ ) adenosine. Provocation of temporary firstgrade AV block ( $n=13$ ) was associated with the longest increment of PR interval, whereas high-grade AV block $(n=36)$
\end{abstract}

produced a significantly shorter PR jump (105 \pm 35 vs. $65 \pm$ $40 \mathrm{~ms}, \mathrm{p}=0.0024$ ). Electrophysiological study and ablation were performed in 37 highly symptomatic patients. AV nodal reentrant tachycardia was diagnosed in 33 patients and orthodromic AV reentrant tachycardia in 4 patients. Conclusion: The adenosine test was characterized by a reverse dose-effect relationship as far as identification of AV nodal duality was concerned.

Copyright $\odot 2007$ S. Karger AG, Basel

\section{Introduction}

The most frequent diagnosis in patients who present with paroxysmal palpitations to an outpatient clinic is atrioventricular nodal reentrant tachycardia (AVNRT) [1]. Since AVNRT depends on the presence of dual atrioventricular (AV) nodal pathways, evidence of dual AV nodal physiology makes the diagnosis of AVNRT very likely [2]. Previous studies demonstrated that administration of adenosine triphosphate or adenosine during sinus rhythm helps to identify the mechanism of supraventricular tachycardia (SVT) in patients presenting with palpitations [3-9]. Moreover, both short-acting drugs have been used to differentiate AVNRT from AV reentrant tachycardia (AVRT) $[5,8]$. The use of this simple noninvasive test may help select patients for early referral

\section{KARGER}

Fax +4161306 1234

E-Mail karger@karger.ch

www.karger.com (c) $2007 \mathrm{~S}$. Karger AG, Basel

1011-7571/07/0165-0339\$23.50/0

Accessible online at:

www.karger.com/mpp
Christiana Schernthaner, MD

Paracelsus Private Medical University, Salzburger Landeskliniken

St. Johanns-Spital, Department of Cardiology, Muellner Haupstrasse 48 AT-5020 Salzburg (Austria)

Tel. +43 6624482 3481, Fax +43 6624482 3486, E-Mail c.schernthaner@salk.at 
Table 1. Clinical characteristics of the patients $(n=57)$

\begin{tabular}{ll}
\hline Variable & Value \\
\hline Age, years & $50 \pm 14^{1}$ \\
Male/female, n (\%) & $21 / 36(37 / 63)$ \\
Structural heart disease, n (\%) & $1(2)$ \\
Ejection fraction $\geq 60 \%, \mathrm{n}(\%)$ & $57(100)$ \\
Duration of arrhythmia, years & $10 \pm 12^{1}$ \\
Palpitations/syncope, n (\%) & $53 / 4(93 / 7)$ \\
Antiarrhythmic medication, n (\%) & $45(79)$ \\
$\quad$ Class I & $23(40)$ \\
$\quad \beta-B l o c k e r s$ & $16(28)$ \\
$\quad$ Class III & $3(5)$ \\
Class IV & $3(5)$
\end{tabular}

${ }^{1}$ Values are expressed as mean \pm standard deviation.

to invasive electrophysiological (EP) evaluation. The purpose of this study was to test the dose-effect relationship of adenosine for the diagnosis of dual AV nodal physiology in patients presenting with palpitations [10].

\section{Subjects and Methods}

\section{Subjects}

The study comprised a total of 57 consecutive patients (21 men, 36 women; age $50 \pm 14$ years) who were referred to the outpatient clinic of our institution with palpitations or syncope suggestive of paroxysmal SVT. A documented index ECG was present in 41 patients showing a narrow QRS tachycardia, which was inconclusive with respect to the underlying mechanism in most of the cases. None of the patients showed a delta wave on the 12-lead surface ECG during sinus rhythm. All patients had a structurally normal heart except one, who presented with moderate aortic valve regurgitation. The baseline characteristics of the patients are shown in table 1.

\section{Adenosine Test}

The adenosine test was performed as a bedside test during sinus rhythm. All patients gave informed consent to this specific pharmacological testing. Adenosine $(3 \mathrm{mg} / \mathrm{ml}$; Ebewe Pharma, Unterach, Austria) was injected through an antecubital vein as a rapid bolus, followed by a 20 -ml flush of normal saline. A 12-lead surface ECG was recorded simultaneously with a paper speed of $25 \mathrm{~mm} / \mathrm{s}$. According to our stepwise clinical protocol, the initial dose was $6 \mathrm{mg}$ adenosine. If a PR jump $\geq 50 \mathrm{~ms}$ was noted on surface ECG or a third-degree AV block occurred, the injection was stopped. In case of no response to the first dose, a bolus of $12 \mathrm{mg}$ adenosine was administered after $5 \mathrm{~min}$. Only those patients who demonstrated neither a significant PR jump nor a high-grade AV block after injection of $12 \mathrm{mg}$ adenosine received an $18-\mathrm{mg}$ bolus of adenosine intravenously after a waiting period of another 5 min. Furthermore, the occurrence of AV nodal echo beats or AV reentrant echo beats was evaluated based on the definition of previous studies $[4,5,8]$. The results were reviewed and graded by two independent electrophysiologists.

\section{EP Study}

Overall, 37 patients underwent invasive evaluation after written informed consent. An EP study was performed in those patients who were highly symptomatic and/or suffered from frequent recurrences of palpitations or arrhythmias. Three quadripolar electrode catheters were introduced through both femoral veins and positioned in the high right atrium, in the His-bundle position and in the apical right ventricle. A luminal decapolar catheter was introduced from the right internal jugular vein into the coronary sinus. Standard EP criteria were used for defining dual AV nodal physiology, AVNRT or AVRT [11]. If AVNRT or AVRT were not inducible with incremental or decremental pacing from the right atrium or ventricle, orciprenaline was administered. After confirmation of the correct diagnosis by various pacing techniques, radiofrequency ablation was performed.

\section{Statistics}

The validity of the test was analyzed by determining the sensitivity (conditional probability that the adenosine bedside test will be positive if the condition, i.e. dual AV nodal physiology, is present during EP study), specificity (conditional probability that the adenosine test will be negative if the condition, i.e. dual AV nodal physiology, is absent during EP study) as well as the positive and negative predictive value for all patients who underwent EP testing. Statistical analysis was performed by unpaired t test. A $p$ value $\leq 0.05$ was considered statistically significant. Data are expressed as mean \pm standard deviation.

\section{Results}

\section{Adenosine Test}

Of the 57 patients, a significant PR jump (mean $99 \pm$ $30 \mathrm{~ms}$ ) was provoked in 21. Abrupt occurrence of thirddegree AV block was noticed in 6 patients. In another 3, SVT was triggered by administration of $6 \mathrm{mg}$ adenosine and no further adenosine testing was performed thereafter. Of the remaining 27 patients, a significant PR increment (mean PR jump $94 \pm 35$ ms) was observed in 13 and 9 developed a transient high-grade AV block. Finally, only $5 / 27$ patients remained in the study to undergo a bolus injection of $18 \mathrm{mg}$ adenosine. One patient refused further adenosine bedside testing because of the transient nonspecific discomfort related to this drug. Consequently, only $4 / 27$ patients received $18 \mathrm{mg}$ adenosine. No significant PR jump was observed in any of the 4 patients. The individual responses were a PR increment of $40 \mathrm{~ms}$ in 3 subjects and a PR increment of $20 \mathrm{~ms}$ in 1 patient (mean PR increment $35 \pm 10 \mathrm{~ms}$ ).

Among all the patients, drug-induced temporary firstdegree AV block was noticed in 13 (23\%), whereas abrupt 
high-grade AV block was observed in 36 (63\%). Provocation of temporary first-grade AV block was associated with the longest increment of PR interval, whereas highgrade AV block was associated with a shorter PR prolongation (PR jump $105 \pm 35 \mathrm{~ms}$ vs. $65 \pm 40 \mathrm{~ms}$, respectively; $\mathrm{p}=0.0024)$. Overall, a positive adenosine test was observed in $34(60 \%)$ patients who demonstrated AV nodal duality at a mean dosage of $8 \pm 3 \mathrm{mg}$. A negative adenosine test was noticed in $23(40 \%)$ patients. The mean adenosine dose leading instantaneously to highgrade AV block without any evidence of AV nodal duality was $9 \pm 4 \mathrm{mg}$. Interestingly, there was no significant difference between the adenosine dosages eliciting dual AV nodal physiology or high-grade AV block $(8 \pm 3 \mathrm{mg}$ vs. $9 \pm 4 \mathrm{mg}$, respectively).

Of the 37 patients that underwent an EP study, a positive adenosine bedside test was noted in 31. A significant PR jump occurred after injection of $6 \mathrm{mg}$ adenosine (PR jump $95 \pm 38 \mathrm{~ms}$ ) in 15 patients and after injection of $12 \mathrm{mg}$ adenosine (PR jump $83 \pm 43 \mathrm{~ms}$ ) in 16 patients. The PR prolongation after bolus application of $18 \mathrm{mg}$ adenosine was $30 \pm 14$ ms. First-degree AV block was associated with longer PR jumps in 11 patients, when compared to the PR increments associated with occurrence of high-grade AV block in 22 patients (PR jump 106 $\pm 36 \mathrm{~ms}$ vs. $73 \pm 41 \mathrm{~ms}$, respectively; $\mathrm{p}=0.029)$. Of note, AV nodal duality was not identified in $6(16 \%)$ patients with the help of the adenosine test but with EP stimulation. Four of these patients with a 'false' negative adenosine test demonstrated high-grade AV block only, whereas the other 2 patients showed no PR prolongation at all despite a dose of $18 \mathrm{mg}$ adenosine.

The results of the adenosine bedside test are summarized in figure 1. Representative ECG examples are shown in figure 2. AV nodal echo beats were noted in 3 patients and $\mathrm{AV}$ reentrant echo beats in 2 patients. Adenosine triggered SVT in 4 patients, but in none of the cases atrial fibrillation. Otherwise, adenosine was tolerated without adverse events.

\section{Results of the EP Study}

Of the 37 patients, AVNRT was diagnosed in 33 patients (age $50 \pm 13$ years) with a mean tachycardia rate of $186 \pm 22 \mathrm{bpm}$. Orthodromic AVRT using an accessory pathway was found in 4 patients (age $31 \pm 10$ years) with a mean tachycardia rate of $194 \pm 21 \mathrm{bpm}$. All patients with AVNRT, but none with AVRT showed a significant AH jump by the atrial extrastimulation technique. After completion of the diagnostic maneuvers, all arrhythmias were successfully treated with radiofrequency ablation.

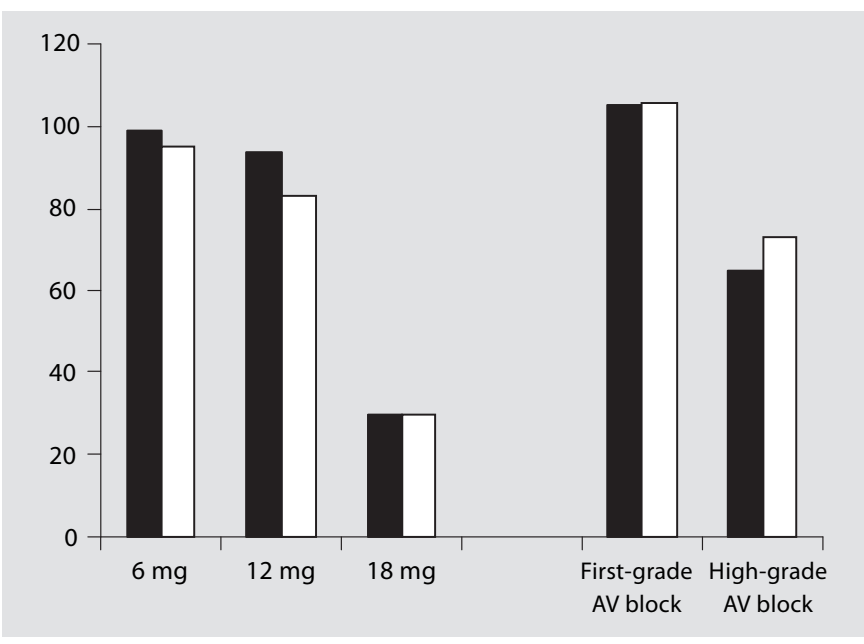

Fig. 1. On the left side of the diagram, the injected adenosine dose is plotted against the drug-induced PR jumps. Note the reverse dose-effect relationship of adenosine as far as the measured PR increments are concerned. On the right side of the diagram, the relationship between the type of AV block and the associated PR jumps is shown. Data are given for the total study group $(\square ; \mathrm{n}=$ 57) and for the subgroup of patients who underwent EP testing $(\square ; n=37)$. The y-axis displays the PR jumps in milliseconds. See text for further details.

\section{Correlation of the Adenosine Bedside Test with the EP} Results

In the AVNRT group, 27 patients demonstrated a significant PR prolongation (PR jump $98 \pm 33 \mathrm{~ms}$ ), whereas only 6 subjects showed no PR jump in the adenosine bedside test. None of the 4 patients with AVRT demonstrated a PR jump $\geq 50 \mathrm{~ms}$. The sensitivity of the adenosine bedside test to detect AV nodal duality related to AVNRT was $82 \%$ and the specificity $100 \%$. The positive predictive value was $100 \%$ and the negative predictive value was $40 \%$.

\section{Discussion}

The results of this study demonstrate a limited doseeffect relationship of adenosine when used for diagnosis of AV nodal duality in patients with symptomatic SVT. Bolus injection of up to $12 \mathrm{mg}$ adenosine provoked a significant PR jump on surface ECG, whereas $18 \mathrm{mg}$ adenosine yielded no additional diagnostic information. Evidence exists from pharmacological studies that the antegrade fast pathway is more sensitive to the effects of adenosine than the slow pathway [3]. If the fast pathway is blocked selectively with adenosine, conduction occurs over the slow pathway, which manifests itself as an in- 


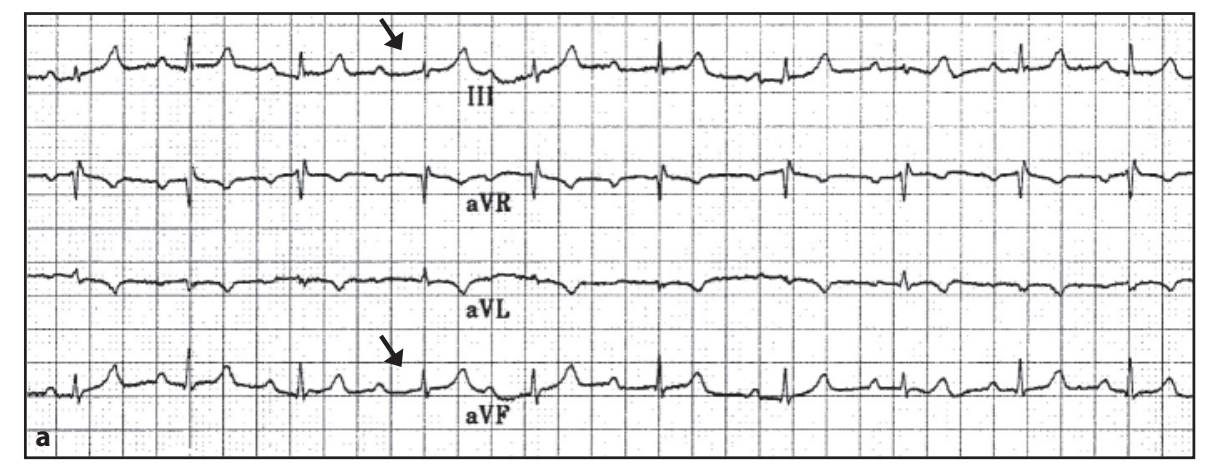

Fig. 2. a Positive adenosine test demonstrating dual AV node physiology. After bolus administration of $6 \mathrm{mg}$ adenosine, a jump of the PR interval from 160 to $280 \mathrm{~ms}$ was noticed on surface ECG (see arrows). b Negative adenosine test due to lack of a significant PR prolongation despite administration of $18 \mathrm{mg}$ adenosine resulting in transient high-grade AV block. The ECG tracings were recorded at a paper speed of $25 \mathrm{~mm} / \mathrm{s}$ and display the surface leads III, aVR, aVL and aVF (a) and the leads I, II and III (b).

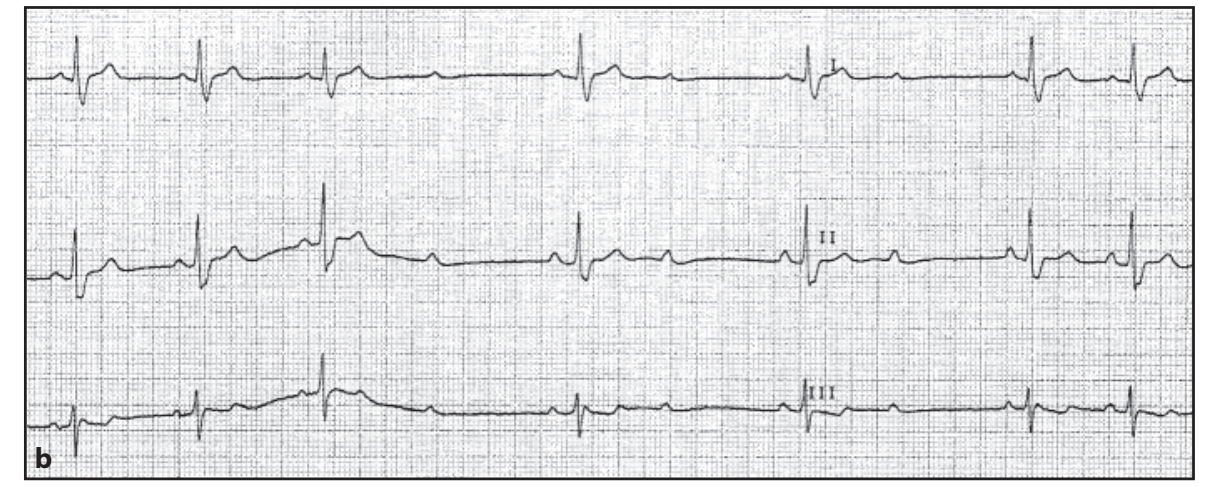

crease in the PR interval. At higher doses, however, the fast pathway is blocked less selectively and high-grade AV block occurs. In this case, both AV nodal inputs are blocked together and discrimination of the two pathways is no longer possible on surface ECG.

The observation that the maximum dose of the drug was not effective to provoke AV block in a few patients has been attributed to the increased sympathetic stimulation caused by adenosine itself. In order to avoid unpleasant and potentially harmful side effects, we recommend avoiding administration of such high adenosine doses. Repetition of the diagnostic bedside test at another time or after a longer resting period is considered to be more effective than adenosine doses exceeding $12 \mathrm{mg}$. In clinical practice, one should always try to administer adenosine at the lowest dose possible to unmask dual AV nodal pathways. The commonly used starting dose of $6 \mathrm{mg}$ adenosine may already result in high-grade AV block due to blockade of both pathways simultaneously. In order to improve the sensitivity of the test, we suggest that a starting dose as low as $3 \mathrm{mg}$ adenosine might be appropriate in some cases. Moreover, smaller dose increments (e.g. $3 \mathrm{mg}$ adenosine) could be helpful to identify silent dual AV nodal physiology.
Belhassen et al. [3-6] evaluated the effect of adenosine triphosphate during sinus rhythm as a valuable tool to diagnose dual AV nodal physiology as well as to differentiate AVNRT from AVRT. In their study, the mean adenosine triphosphate dose was $19.3 \pm 8.5 \mathrm{mg}$ for diagnosing dual AV nodal physiology and $15.6 \pm 6 \mathrm{mg}$ for differentiating between both types of SVT [3,5]. Moro et al. [12] reported a dose-related efficacy of adenosine triphosphate for termination of spontaneous SVTs. Side effects, such as sinus pauses and bradycardia following termination of the arrhythmia, were directly correlated with the dose employed. Other investigators focused their interest on the pharmacological effects of the very short-acting drug adenosine $[7,8,13]$. Burkart et al. [13] used a mean dose of $7.1 \pm 3.9 \mathrm{mg}$ adenosine to block the AV node while pacing the atrium. Tebbenjohanns et al. [7] investigated the value of the adenosine test in 37 patients and found that the mean dose to show dual AV nodal physiology or to produce AV block was $10.3 \mathrm{mg}$ adenosine. Toal et al. [8] tested a single dose of $12 \mathrm{mg}$ adenosine and reported a sensitivity of $74 \%$ and a specificity of $94 \%$. In accordance with the latter results, we found a sensitivity of $82 \%$ and a specificity of $100 \%$, confirming the observation that higher doses of adenosine (i.e. more than $12 \mathrm{mg}$ ) do not improve the diagnostic value of this simple non- 
invasive test. The incidence of $\mathrm{AV}$ nodal echo beats was about $5 \%$ in our study, which is similar to that reported by Toal et al. [8] but definitely lower than that reported by Belhassen et al. [3] (48\%) or Tebbenjohanns et al. [7] (23\%). AV reentrant echo beats were seen in 2 of the 4 patients with a concealed accessory pathway.

A major limitation of this study is the small number (4) of patients receiving $18 \mathrm{mg}$ adenosine. However, in the light of a clinically driven study there was no reason to administer higher doses of adenosine once dual AV nodal physiology or high-grade AV block were elicited by lower dosages. Another limitation was that a relatively small number of patients (37) with AVRT were included in our study. None of our patients with AVRT presented dual AV nodal physiology in addition to the accessory pathway. However, the clinician has to keep in mind that dual AV nodal pathways may be present in patients with AVRT in up to $40 \%$ resulting in double tachycardias [14]. Although we did not observe any adverse event beside the typical vasodilatory effects of the drug, application of adenosine - particularly in higher doses - should only be performed under specific precautions and in an environment where resuscitation is feasible. Serious complications and life-threatening conditions despite the very short half-life of the drug have been reported $[15,16]$.

\section{Conclusion}

The results of this study demonstrate that adenosine has a limited dose-effect relationship in unmasking AV nodal duality. Thus, the lowest dose possible to get the differential effect on dual AV nodal pathways is preferred. In the present study, a bolus of 6-12 mg adenosine turned out to be effective for selective blockade of the fast pathway, manifesting itself in a significant PR jump on the surface ECG. Consequently, the induction of first-grade AV block was more predictive of the presence of dual AV nodal physiology than high-grade AV block. The adenosine bedside test is a safe and useful measure for detection of dual AV nodal physiology during normal sinus rhythm with a high sensitivity and specificity.

\section{References}

1 Gaita F, Riccardi R, Marco S, Caponi D: Catheter ablation of typical atrioventricular nodal reentrant tachycardia; in Zipes DP, Haissaguerre M (eds): Catheter Ablation of Arrhythmias. New York, Futura Publishing Company Inc, 2002, pp 225-248.

-2 Denes P, Wu D, Dhingra RC, Chuquimia R, Rosen KM: Demonstration of dual A-V nodal pathways in patients with paroxysmal supraventricular tachycardia. Circulation 1973;48:549-555.

-3 Belhassen B, Fish R, Glikson M, Glick A, Eldar M, Laniado S, Viskin S: Noninvasive diagnosis of dual AV node physiology in patients with AV nodal reentrant tachycardia by administration of adenosine- 5 -triphosphate during sinus rhythm. Circulation 1998;98:47-53.

4 Belhassen B, Fish R, Viskin S, Glick A, Glikson M, Eldar M: Adenosine-5'-triphosphate test for the noninvasive diagnosis of concealed accessory pathway. J Am Coll Cardiol 2000;36:803-810.

$\checkmark 5$ Viskin S, Fish R, Glick A, Glikson M, Eldar $\mathrm{M}$, Belhassen B: The adenosine triphosphate test: a bedside diagnostic tool for identifying the mechanism of supraventricular tachycardia in patients with palpitations. J Am Coll Cardiol 2001;38:173-177.
6 Belhassen B: Adenosine triphosphate in cardiac arrhythmias: from therapeutic to diagnostic use. Pacing Clin Electrophysiol 2002; 25:98-102.

7 Tebbenjohanns J, Niehaus M, Korte T, Drexler $\mathrm{H}$ : Noninvasive diagnosis in patients with undocumented tachycardias: value of the adenosine test to predict AV nodal reentrant tachycardia. J Cardiovasc Electrophysiol 1999;10:916-923.

8 Toal SC, Vajifdar BU, Gupta AK, Vora AM, Lokhandwala YY: Adenosine induced PR jump on surface ECG to differentiate atrioventricular nodal re-entrant tachycardia from concealed accessory pathway mediated tachycardia: a bedside test. Heart 2002;87: 37-40.

$\checkmark 9$ Strohmer B: Rate-dependent left bundle branch block unmasked by adenosine. Int J Cardiol 2005;103:219-220.

10 Schernthaner C, Strohmer B, Pichler M: Limited dose-effect relationship of adenosine for detection of AV nodal duality in patients with supraventricular tachycardias. Europace 2005;7(suppl):185.

11 Josephson ME: Clinical Cardiac Electrophysiology: Techniques and Interpretations, ed 3. Baltimore, Lippincott Williams \& Wilkins, 2002.
12 Moro C, Lorio N, Nunez A, Martinez J, Novo L, Aguilera M, Madrid AH: Dose related efficacy of adenosine triphosphate in spontaneous supraventricular tachyarrhythmias. Int J Cardiol 1989;25:207-212.

13 Burkart TA, Scozzaro MJ, Angella FR, Jayaram KN, Gonzalez MD, Conti JB, Curtis $\mathrm{AB}$ : Use of adenosine as a diagnostic tool for dual atrioventricular nodal pathways: response of control patients to incremental doses of adenosine. Clin Cardiol 2002;25: 263-266

14 Farshidi A, Josephson ME, Horowitz LN: Electrophysiologic characteristics of concealed bypass tracts: clinical and electrocardiographic correlates. Am J Cardiol 1978;41: 1052-1060.

15 Brodsky MA, Hwang C, Hunter D, Chen PS, Smith D, Ariani M, Johnston WD, Allen BJ, Chun JG, Gold CR: Life-threatening alterations in heart rate after the use of adenosine in atrial flutter. Am Heart J 1995;130:564571.

16 Zehender M, Jeron A, Faber T, Brunner M, Just $\mathrm{H}$ : Adenosine in treating cardiac arrhythmias. J Auton Pharmacol 1996;16:329331. 